\title{
Effect of a seagrass (Posidonia oceanica) meadow on wave propagation
}

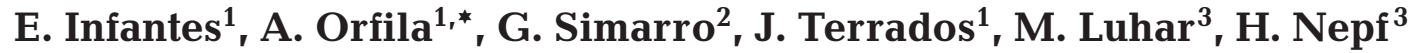 \\ ${ }^{1}$ Instituto Mediterráneo de Estudios Avanzados (CSIC-UIB), 07190 Esporles, Spain \\ ${ }^{2}$ Institut de Ciències del Mar, ICM-CSIC, 08003 Barcelona, Spain \\ ${ }^{3}$ Department of Civil and Environmental Engineering, Massachusetts Institute of Technology, Cambridge, \\ Massachusetts 02139-4307, USA
}

\begin{abstract}
We demonstrate the utility of using the equivalent bottom roughness for calculating the friction factor and the drag coefficient of a seagrass meadow for conditions in which the meadow height is small compared to the water depth. Wave attenuation induced by the seagrass Posidonia oceanica is evaluated using field data from bottom-mounted acoustic doppler velocimeters (ADVs). Using the data from one storm event, the equivalent bottom roughness is calculated for the meadow as $k_{\mathrm{s}} \sim 0.40 \mathrm{~m}$. This equivalent roughness is used to predict the wave friction factor $f_{\mathrm{w}}$, the drag coefficient on the plant, $C_{\mathrm{D}}$, and ultimately the wave attenuation for other storms. Root mean squared wave height $\left(H_{\mathrm{rms}}\right)$ is reduced by around $50 \%$ for incident waves of $1.1 \mathrm{~m}$ propagating over $\sim 1000 \mathrm{~m}$ of a meadow of $P$. oceanica with shoot density of $\sim 600$ shoots $\mathrm{m}^{-2}$.
\end{abstract}

KEY WORDS: Wave attenuation - Posidonia oceanica - Seagrass meadow · Bottom roughness · Friction coefficient $\cdot$ Drag coefficient $\cdot$ Wave damping

Resale or republication not permitted without written consent of the publisher

\section{INTRODUCTION}

Sediment stabilization and coastal protection are key ecosystem services provided by seagrasses, aquatic angiosperms that colonize shallow marine habitats (Hemminga \& Nieuwenhuize 1990, Fonseca 1996, Koch et al. 2009). Submerged plants increase bottom roughness, thus reducing near-bed velocity and modifying the sediment transport (Koch et al. 2006) and increasing wave attenuation (Kobayashi et al. 1993, Méndez \& Losada 2004). In addition, seagrass rhizomes and roots extend inside sediment and contribute to its stabilization (Fonseca 1996).

Flume and in situ measurements have shown that water velocity is reduced inside meadows. In sparse canopies, turbulent stress remains elevated within the canopy, while in dense canopies turbulent stress is reduced by canopy drag near the bed (Luhar et al. 2008). The reduction in velocity due to seagrass canopies is lower for wave-induced flows compared to unidirectional flows, because the inertial term can be larger or comparable to the drag term in oscillatory flow (Lowe et al. 2005, Luhar et al. 2010). Except for intertidal systems, where currents are dominant, most seagrass meadows lie in wave-dominated habitats. Interaction between seagrass canopies and oscillatory flow has, however, been much less studied than the interaction with currents. Near-bed turbulence levels inside seagrass canopies are lower than those on sands under wave-generated oscillatory flows (Granata et al. 2001). Wave energy and sediment resuspension are also reduced by seagrasses (Terrados \& Duarte 2000, Verduin \& Backhaus 2000, Gacia \& Duarte 2001).

Wave attenuation by seagrass canopies has been measured only in shallow systems where canopies occupy a large fraction of the water column (Fonseca \& Cahalan 1992, Koch \& Beer 1996, Mork 1996, Chen et al. 2007, Bradley \& Houser 2009). Posidonia oceanica, which is the dominant seagrass species in the 
Mediterranean Sea, forms extensive meadows in depths up to $45 \mathrm{~m}$ (Procaccini et al. 2003) and the canopy often occupies less than $20 \%$ of water column height. Although commonly assumed to occur (Luque \& Templado 2004, Boudouresque et al. 2006), wave attenuation by $P$. oceanica meadows, or by any meadow occupying a small fraction of the water column, has not been accurately assessed in the field. In this study we evaluate the effect of a $P$. oceanica seagrass meadow on wave propagation under natural conditions. To quantify wave attenuation due to $P$. oceanica meadow in the field, we measure wave heights and orbital velocities along a transect above the meadow for 3 storms.

Most coastal models introduce bottom effects through the equivalent roughness, $k_{\mathrm{s}}$, and therefore it is practical to consider if such a characterization can apply to seagrasses. The equivalent roughness will be used to account for the effects of both the sandy bed and the meadow. Moreover, Bradley \& Houser (2009) already suggested the use of an equivalent roughness to describe wave attenuation due to a canopy, but to date, no attempt has been made to relate this quantity to the drag coefficient which describes the drag associated with the individual blades. The underlying assumptions of our approach are, first, that the boundary layer is rough turbulent and, second, that water depth is much larger than the blade length.

\section{MATERIALS AND METHODS}

The bottom boundary layer is the region in which the velocity field drops from the value in the core of the fluid to zero at the bed. In a bottom covered by seagrass the boundary layer is modified by the canopy, which influences the mean velocity, turbulence and mass transport (e.g. Nepf \& Vivoni 2000, Ghisalberti \& Nepf 2002, Luhar et al. 2010). In this analysis, we assume that the seagrass exists within the bottom boundary layer and thus can be represented as a bottom roughness. A list of symbols used in the analysis is given in Table 1.

The dimensionless parameter relating the velocity outside the boundary layer, $u_{\mathrm{b}}$, and the bed shear stress transmitted to the combined seagrass and bottom, $\tau_{\mathrm{b}}$, is the wave friction factor defined as $f_{\mathrm{w}} \equiv$ $2\left|\tau_{\mathrm{b}}\right| / \rho u_{\mathrm{b}}^{2}$, where $\rho$ is the fluid density. The friction factor $f_{\mathrm{w}}$ depends on the Reynolds number, $u_{\mathrm{b}}^{2} / v \omega$, and on the relative roughness, $k_{\mathrm{s}} \omega / u_{\mathrm{b}}$. Here, $v$ is the kinematic viscosity of the water, $\omega$ the wave angular frequency ( $\omega=2 \pi / T$, with $T$ the wave period), and $k_{\mathrm{s}}$
Table 1. Symbols used in the paper

\begin{tabular}{|c|c|}
\hline a & Wave amplitude (m) \\
\hline$a_{b}$ & Orbital wave excursion $\left(\mathrm{m} \mathrm{s}^{-1}\right)$ \\
\hline$a_{V}^{\prime}$ & Plant surface area per unit height (m) \\
\hline$b$ & Characteristic length of the plant (m) \\
\hline$C_{\mathrm{g}}$ & Group velocity $\left(\mathrm{m} \mathrm{s}^{-1}\right)$ \\
\hline$C_{\mathrm{D}}$ & Drag coefficient \\
\hline$C_{\mathrm{D}, \mathrm{SG}}$ & $\begin{array}{l}\text { Drag coefficient as defined by Sánchez- } \\
\text { Gonzáles et al. (2011) }\end{array}$ \\
\hline$E$ & Wave energy $\left(\mathrm{J} \mathrm{m}^{-2}\right)$ \\
\hline$f_{\mathrm{w}}$ & Wave friction coefficient \\
\hline$g$ & Acceleration of gravity $\left(\mathrm{m} \mathrm{s}^{-2}\right)$ \\
\hline$h$ & Water depth (m) \\
\hline$H_{\mathrm{rms}}$ & Root mean squared wave height (m) \\
\hline$H_{\mathrm{rms}, 0}$ & Incident root mean squared wave height $(\mathrm{m})$ \\
\hline$H_{\mathrm{rms}, i}^{\mathrm{c}}$ & Computed wave heights (m) \\
\hline$H_{\mathrm{rms}, i}^{\mathrm{m}}$ & Measured wave heights (m) \\
\hline$k_{\mathrm{p}}$ & Peak wave number $\left(\mathrm{m}^{-1}\right)$ \\
\hline$k_{\mathrm{s}}$ & Bottom equivalent roughness (m) \\
\hline$\gamma$ & Wave attenuation coefficient $\left(\mathrm{m}^{-1}\right)$ \\
\hline$\dot{\lambda}_{\mathrm{p}}$ & Peak wave length (m) \\
\hline$l_{V}$ & Vegetation length (m) \\
\hline$N$ & Number of shoots per unit area $\left(\mathrm{m}^{-2}\right)$ \\
\hline$T, T_{\mathrm{p}}$ & Wave period and wave peak period (s) \\
\hline$u^{\mathrm{P}}$ & Fluid velocity $\left(\mathrm{m} \mathrm{s}^{-1}\right)$ \\
\hline$u_{\mathrm{b}}$ & Near-bottom orbital velocity $\left(\mathrm{m} \mathrm{s}^{-1}\right)$ \\
\hline$x$ & Horizontal distance (m) \\
\hline$\varepsilon_{\mathrm{D}}$ & Rate of energy dissipation $\left(\mathrm{J} \mathrm{m}^{-2} \mathrm{~s}^{-1}\right)$ \\
\hline$\rho$ & Seawater density $\left(\mathrm{kg} \mathrm{m}^{-3}\right)$ \\
\hline$\tau_{\mathrm{b}}$ & Bottom shear stress $\left(\mathrm{N} \mathrm{m}^{-2}\right)$ \\
\hline$v$ & Kinematic viscosity of water $\left(\mathrm{m}^{2} \mathrm{~s}^{-1}\right)$ \\
\hline$\omega$ & Wave angular frequency $\left(\mathrm{s}^{-1}\right)$ \\
\hline
\end{tabular}

a length characterizing the bottom equivalent roughness. For bare beds, the equivalent roughness, $k_{\mathrm{s}}$ is related to the sediment size and the bed form height. If the boundary layer is smooth (namely $k_{s} \sqrt{\tau_{\mathrm{b}} / \rho} / \nu \lesssim$ $3.3)$, then $f_{\mathrm{w}}$ depends mainly on the Reynolds number. Otherwise, if the boundary layer is rough $\left(k_{s} \sqrt{\tau_{\mathrm{b}} / \rho} / \nu \gtrsim 3.3\right)$, the friction factor depends mainly on the relative roughness. At this point, we assume that the boundary with seagrass is rough, and we will later check this assumption.

Accounting for signs, the definition of $f_{\mathrm{w}}$ implies $\tau_{\mathrm{b}}=\rho f_{\mathrm{w}} u_{\mathrm{b}}\left|u_{\mathrm{b}}\right| / 2$. Though this approach is valid as a first order approximation, it is known to be an oversimplification of the problem. For instance, it is well known that the shear under monochromatic waves is not in phase with velocity. This has led to modifications of the friction factor to introduce the phase lag (Nielsen 1992), and to redefine the friction factor as (Jonsson 1967) $f_{\mathrm{w}} \equiv 2 \tau_{\mathrm{b}, \max } / \rho u_{\mathrm{b}, \max }^{2}$, where the subscript refers to the maximum value of the variable within a wave period. With this redefinition, for rough conditions, the friction factor proposed by Nielsen (1992) as a modification of the semi-empirical formula of Swart (1974) for sandy bottoms is: 


$$
f_{\mathrm{w}}=\exp \left\{5.5\left(\frac{k_{\mathrm{s}} \omega}{u_{\mathrm{b}}}\right)^{0.2}-6.3\right\}
$$

Recent work (e.g. Méndez \& Losada 2004, SánchezGonzález et al. 2011) suggests that the friction due to seagrasses can be determined in terms of the Keulegan-Carpenter number (i.e. KC $\equiv u T / b$ with $u$ a characteristic velocity of the flow and $b$ a characteristic length of the plant, usually the width). Assuming that the boundary layer generated by the vegetation is rough, and noting that $\mathrm{KC}^{-1}$ has the same functional structure as the relative roughness $k_{s} \omega / u_{\mathrm{b}}$, we propose the use of Eq. (1) for $f_{\mathrm{w}}$ with $k_{\mathrm{s}}$ being the equivalent roughness of the seagrass meadow.

Assuming that linear wave theory is valid and assuming straight and parallel bathymetric contours, the conservation of wave energy for random waves may be written as

$$
\frac{\partial\left(E C_{g}\right)}{\partial x}=-\varepsilon_{D}
$$

with the energy $E$ being $E \equiv \rho g H_{\text {rms }}^{2} / 8$, with $g$ the acceleration of gravity, $H_{\text {rms }}$ the root mean squared wave height, $\varepsilon_{\mathrm{D}}$ the energy dissipation, and $c_{\mathrm{g}}$ the group velocity given by

$$
C_{\mathrm{g}}=\frac{\omega}{2 k_{\mathrm{p}}}\left\{1+\frac{2 k_{\mathrm{p}} h}{\sinh \left(2 k_{\mathrm{p}} h\right)}\right\}
$$

with the peak wave number, $k_{\mathrm{p}}=2 \pi / \lambda_{\mathrm{p}}$, where $\lambda_{\mathrm{p}}$ is the wave length corresponding to the peak period $\left(T_{\mathrm{p}}\right)$, and $h$ the local water depth.

Previous theoretical, numerical and observational works on wave propagation over vegetated fields have dealt with the question of obtaining the dissipation term, $\varepsilon_{\mathrm{D}}$, in order to integrate Eq. (2) (Kobayashi et al. 1993, Méndez \& Losada 2004, Bradley \& Houser 2009). The dissipation term is

$$
\varepsilon_{\mathrm{D}}=\overline{\tau_{\mathrm{b}} u_{\mathrm{b}}}=\frac{1}{2} \rho f_{\mathrm{w}} \overline{\left|u_{\mathrm{b}}\right| u_{\mathrm{b}}^{2}}
$$

with the overbar standing for time average. We define $I_{V}$ as the canopy height and use linear wave theory to describe the time-varying wave-induced velocity at the top of the canopy, $z=-h+l_{V}$. Then, following the procedure proposed by Méndez \& Losada (2004) to handle irregular waves, Eq. (4) becomes

$$
\varepsilon_{\mathrm{D}}=\frac{\rho f_{\mathrm{w}}}{2 \sqrt{\pi}}\left(\frac{g k_{\mathrm{p}}}{2 \omega_{\mathrm{p}}}\right)^{3} \frac{\cosh ^{3}\left(k_{\mathrm{p}} l_{\mathrm{V}}\right)}{\cosh ^{3}\left(k_{\mathrm{p}} h\right)} H_{r m s}^{3}
$$

Alternatively, following Dalrymple et al. (1984), Méndez \& Losada (2004) obtained the dissipation in terms of the blade drag coefficient, $C_{\mathrm{D}}$,

$$
\varepsilon_{\mathrm{D}}=\frac{\rho C_{\mathrm{D}} a_{\mathrm{V}}^{\prime} N}{6 \sqrt{\pi k_{\mathrm{p}}}}\left(\frac{g k_{\mathrm{p}}}{2 \omega_{\mathrm{p}}}\right)^{3} \frac{\sinh ^{3}\left(k_{\mathrm{p}} l_{V}\right)+3 \sinh \left(k_{\mathrm{p}} l_{\mathrm{V}}\right)}{\cosh ^{3}\left(k_{\mathrm{p}} h\right)} H_{\mathrm{ms}}^{3}
$$

where $N$ is the number of plants per unit of horizontal area, and $a_{V}^{\prime}$ is the plant area per unit height. A similar approach is used by Plew et al. (2005) to describe wave interaction with the suspended ropes of a mussel farm. By comparing Eqs. (5) \& (6), the relationship between the friction coefficient $f_{\mathrm{w}}$ and the drag coefficient $C_{\mathrm{D}}$ follows, which for $k_{\mathrm{p}} l_{V} \ll 1$ reduces to

$$
f_{\mathrm{w}}=C_{\mathrm{D}} a_{V}^{\prime} l_{V} N
$$

If the equivalent roughness $k_{\mathrm{s}}$ of a Posidonia oceanica meadow can be found, as we propose, the friction coefficient $f_{\mathrm{w}}$ (and, therefore, $\varepsilon_{\mathrm{D}}$ ) can be computed through Eqs. (1) \& (5). For irregular waves, we consider $u_{\mathrm{b}, \mathrm{rms}}$ as the corresponding velocity in Eq. (1). Once $\varepsilon_{\mathrm{D}}$ is estimated at each point, the wave height $H_{\text {rms }}$ can be computed by integrating Eq. (2). We use a finite difference scheme for numerical integration.

The wave attenuation over a constant depth has received special attention in the literature. Assuming $C_{\mathrm{D}}$ constant in Eq. (6), Dalrymple et al. (1984) and Méndez \& Losada (2004) analytically integrated Eq. (2) to get

$$
H_{\mathrm{rms}}=\frac{H_{\mathrm{rms}, 0}}{1+\gamma X}
$$

with $H_{\mathrm{rms}, 0}=H_{\mathrm{rms}}(x=0)$ and where the attenuation coefficient $\gamma\left(\mathrm{m}^{-1}\right)$ is

$$
\gamma=\frac{C_{\mathrm{D}} a_{V}^{\prime} N}{3 \sqrt{\pi}} \frac{\sinh ^{3}\left(k_{\mathrm{p}} l_{V}\right)+3 \sinh \left(k_{\mathrm{p}} l_{V}\right)}{\left(\sinh 2 k_{\mathrm{p}} h+2 k_{\mathrm{p}} h\right) \sinh \left(k_{\mathrm{p}} h\right)} k_{\mathrm{p}} H_{\mathrm{rms}, 0}
$$

Similarly, for wave propagation over constant depth, if we assume constant $f_{\mathrm{w}}$, the above solution (Eq. 8) would also hold for our approach, now being

$$
\gamma=\frac{f_{\mathrm{w}} k_{\mathrm{p}}}{\sqrt{\pi}} \frac{\sinh ^{3}\left(k_{\mathrm{p}} l_{V}\right)}{\left(\sinh 2 k_{\mathrm{p}} h+2 k_{\mathrm{p}} h\right) \sinh \left(k_{\mathrm{p}} h\right)} k_{\mathrm{p}} H_{\mathrm{rms}, 0}
$$

Using the solution in Eq. (8), the wave attenuation per wavelength, $1-H_{\mathrm{rms}}\left(x=\lambda_{\mathrm{p}}\right) / H_{\mathrm{rms}, 0}$, is $1-\left(1+\gamma \lambda_{\mathrm{p}}\right)^{-1}$.

Departing from a different differential equation, Kobayashi et al. (1993) and Sánchez-González et al. (2011) obtain the following solution for the constant depth case

$$
H_{\mathrm{rms}}=H_{\mathrm{rms}, 0} \exp (-\gamma x)
$$

with $\gamma$ given in Eq. (9) for Kobayashi et al. (1993) and a slightly different expression for Sánchez-González et al. (2011). Differences between Eqs. (8) \& (10) are $<10 \%$ up to $\gamma x \lesssim 0.5$.

\section{Field measurements}

Field measurements were carried out in Cala Millor, on the northeast coast of the island of Mallorca, 
Mediterranean Sea (Fig. 1a-c). Cala Millor is an intermediate barred sandy beach formed by biogenic sediments with median grain values ranging between 0.28 and $0.38 \mathrm{~mm}$ at the beach front (Gómez-Pujol et al. 2007). The beach is in an open bay with an area of about $14 \mathrm{~km}^{2}$. At depths from 6 to $35 \mathrm{~m}$, the seabed is covered with a meadow of Posidonia oceanica (Infantes et al. 2009). The bay is microtidal, with a spring range of less than $0.25 \mathrm{~m}$ (Orfila et al. 2005), and the near-bottom mean currents during the period of study were small $\left(<0.05 \mathrm{~m} \mathrm{~s}^{-1}\right)$. The bay is located on the east coast of the island, and is therefore exposed to incoming wind and waves from NE to ESE directions.

From 7 to 23 July 2009, 4 self-contained Acoustic Doppler Velocimeters ADVs (Nortek, Vector) with pressure sensors were deployed on a transect perpendicular to the coast at depths of 6.5,10,12.5 and $16.5 \mathrm{~m}$ and of total length $942 \mathrm{~m}$ (Fig. 1d). ADVs were mounted over galvanized iron structures, with the pressure sensors located at 80 to $100 \mathrm{~cm}$ above the bottom, i.e. just above the seagrass canopy (Fig. 2). Stabil-

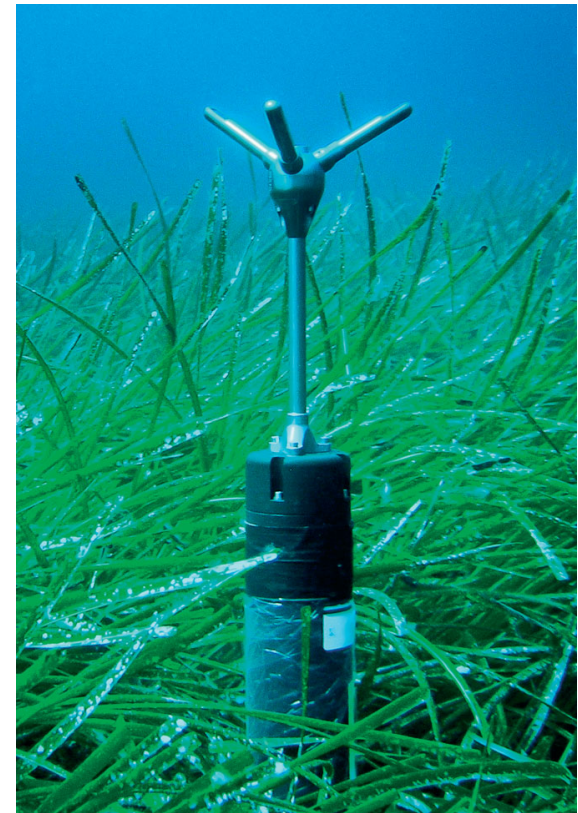

Fig. 2. Acoustic doppler velocimeter (ADV) deployed in the Posidonia oceanica seagrass meadow
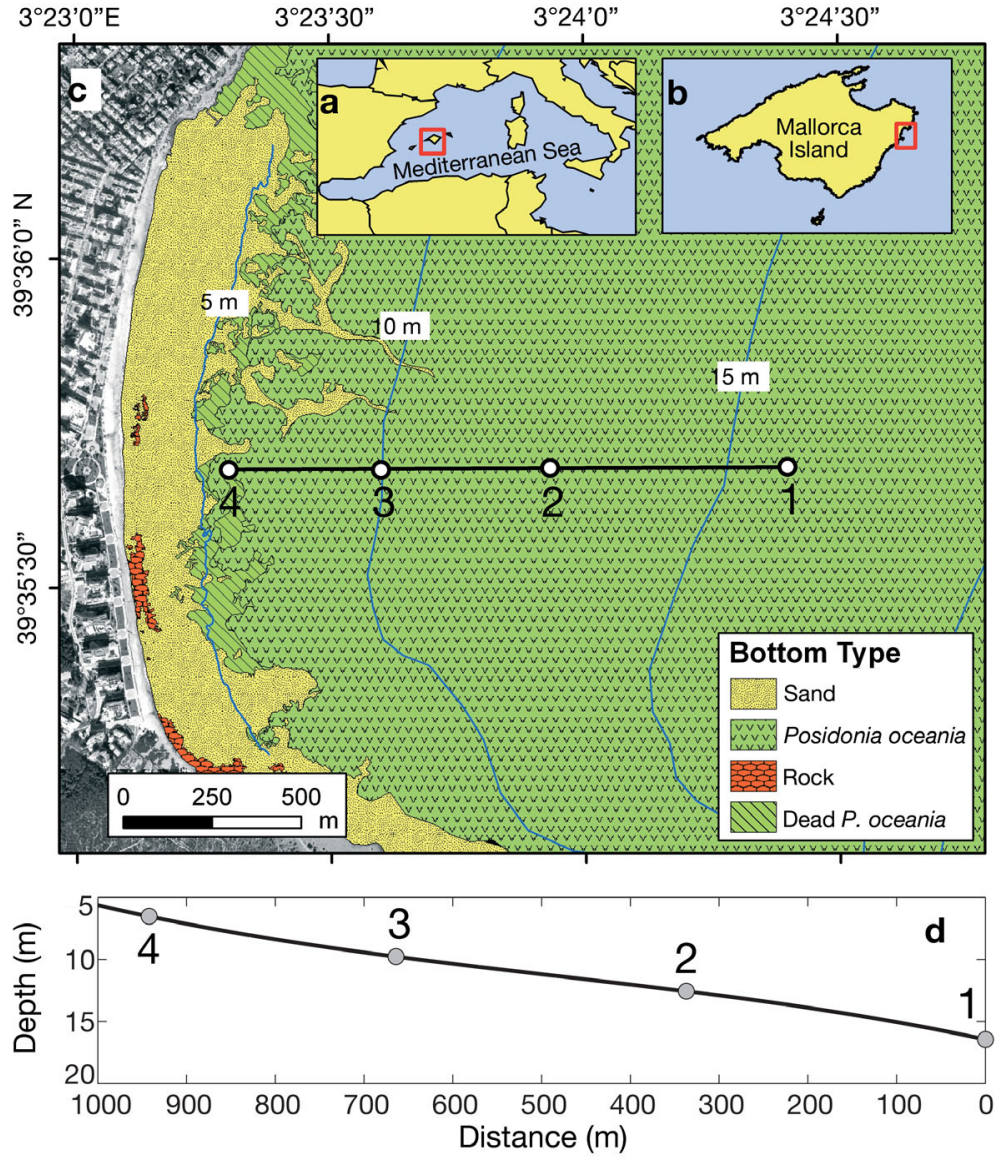

Fig. 1. Locations of (a) the island of Mallorca in the Mediterranean Sea, (b) the study area, (c) the transect and deployment sites in Cala Millor.

(d) Bathymetric profile and distance between the deployment sites ity of the equipment was verified with compass, tilt and roll sensors (Infantes et al. 2011). Velocity data were collected at 80 to $100 \mathrm{~cm}$ above the bottom in bursts of 15 min every $2 \mathrm{~h}$ at a sampling rate of $4 \mathrm{~Hz}$, sampling volume given as $14.9 \mathrm{~mm}$ and a nominal fluid velocity range of $\pm 1 \mathrm{~m} \mathrm{~s}^{-1}$. With this sampling rate we were able to capture waves with a period above $2 \mathrm{~s}$. For waves with periods below $2 \mathrm{~s}$, linear wave theory indicates that the velocities transmitted to the bottom are negligible compared to those corresponding to the peak period.

Root mean squared wave height $\left(H_{\text {rms }}\right)$, horizontal components of velocity $\left(u_{\mathrm{b}, \mathrm{rms}}\right.$ and $\left.V_{\mathrm{b}, \mathrm{rms}}\right)$, and peak period $\left(T_{\mathrm{p}}\right)$ were processed using Nortek (QuickWave v.2.04) software (Nortek 2002). Wave data were filtered to remove waves not approaching perpendicular to the beach. To exclude wave energy lost by white capping, we excluded wave records when mean wind velocities were higher than $10 \mathrm{~m} \mathrm{~s}^{-1}$ (data from the Spanish Harbor Authority 'Puertos del Estado').

The area is subject to cyclogenetic activity throughout the year (Cañellas et al. 2007). Indeed, during the instrument deployment, 3 events with $H_{\text {rms }}$ larger than $0.60 \mathrm{~m}$ at the deepest location (significant wave height, $H_{\mathrm{s}}>0.85 \mathrm{~m}$ ) affected the area (Fig. 3a). Hereafter 'storms' refer to events where the signifi- 

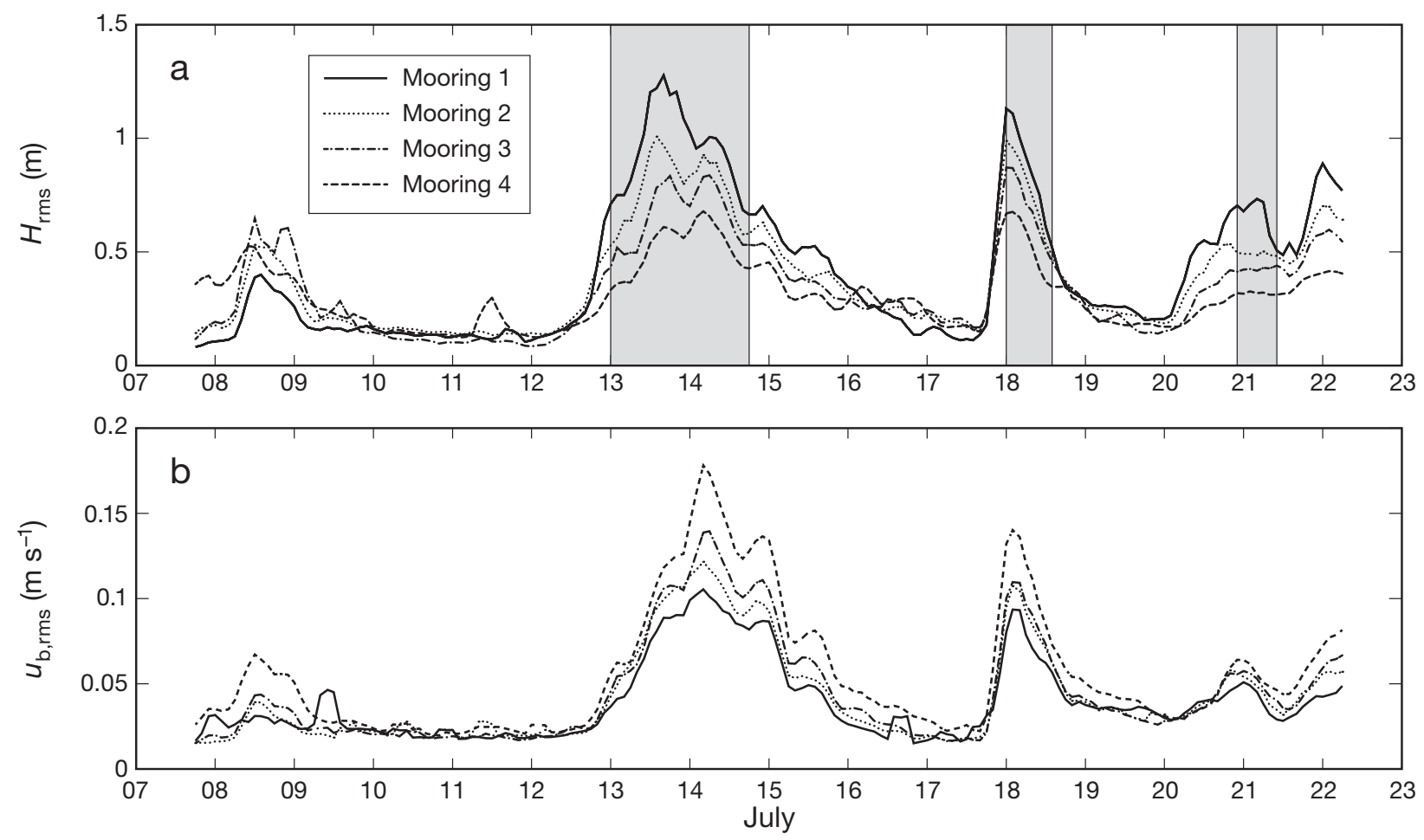

Fig. 3. (a) Root mean squared wave height, $H_{\mathrm{rms}}$ at mooring 1 (16.5 m depth); mooring 2 (12.5 m); mooring 3 (10 m) and mooring $4(6.5 \mathrm{~m})$. Grey areas indicate the 3 storms. (b) Corresponding near-bottom orbital velocities at the same locations

cant wave height is large, regardless of local wind conditions. The first storm began on 13 July and lasted $44 \mathrm{~h}$ with a maximum $H_{\mathrm{rms}}$ of $1.31 \mathrm{~m}$. The second storm began on 18 July, lasted $16 \mathrm{~h}$ and reached $H_{\text {rms }}=1.19 \mathrm{~m}$. The third storm began on 21 July, lasted $14 \mathrm{~h}$ and reached $H_{\mathrm{rms}}=0.74 \mathrm{~m}$. The equivalent roughness of the meadow, $k_{\mathrm{s}}$, which is assumed to remain essentially constant for all storms, was calculated from the third storm and then used to compute, integrating Eq. (2), the wave attenuation for the first 2 storms. The computed wave attenuation was then compared to the corresponding experimental data.

\section{Determination of equivalent roughness}

As stated, the equivalent roughness $k_{\mathrm{s}}$ is a critical parameter for the characterization of the friction factor in rough turbulent flows. We expect it to be a function of the meadow morphology (number of shoots, shoot height and leaf width mainly), and it will be assumed to be constant during the experimental duration. This is a fair assumption since all measurements were done in summer over a short period of time (16 d). Posidonia oceanica leaf lengths and leaf widths were measured for 10 vertical shoots collected at locations 1 to 4 (Fig. 1, top). The mean shoot length, $1_{V}$, was $0.8 \pm 0.1 \mathrm{~m}$ (mean $\pm \mathrm{SE}$ ) and leaf surface area per plant $211 \pm 23 \mathrm{~cm}^{2}$ (mean $\pm \mathrm{SE}$ ), so that $a_{V}^{\prime} \approx 0.0264 \mathrm{~m}$. Shoot density, $N$, was also measured at the same 4 locations, and was $615 \pm 34 \mathrm{~m}^{-2}$ (mean $\pm \mathrm{SE}$ ).

Velocities and wave heights measured along the transect during the third storm (21 July) were used to obtain $k_{\mathrm{s}}$. Specifically, we found the value of $k_{\mathrm{s}}$ that minimizes the error

$$
\sqrt{\sum_{i=2}^{4}\left|H_{\mathrm{rms}, i}^{\mathrm{c}}-H_{\mathrm{rms}, i}^{\mathrm{m}}\right|^{2}}
$$

between the observed and computed wave heights, where $i=2,3,4$ correspond to moorings 2 to 4 (at $x=$ 337, 664 and $942 \mathrm{~m}$ respectively). In Eq. (11), $H_{\mathrm{rms}, i}^{\mathrm{m}}$ are the measured values and $H_{\mathrm{rms}, i}^{\mathrm{c}}$ are the values computed by integrating Eq. (2) starting from the value measured at the first mooring, i.e. $H_{\mathrm{rm}, i}^{\mathrm{m}}$. In the numerical integration, the bathymetry was adjusted by fitting a third order polynomial to the depths at the 4 moorings (Fig. 1d).

The value of $k_{\mathrm{s}}$ minimizing the above error was computed for a total of $14 \mathrm{~h}$ corresponding to the third storm, and the average for all records was calculated. Once $k_{\mathrm{s}}$ was determined for the Posidonia 
oceanica meadow, we computed $f_{\mathrm{w}}$ and wave attenuation for the other 2 storms, and compared the computed results with the field measurements to validate the model approach. To obtain $f_{W}$ from Eq. (1) we always assumed purely oscillatory motion; this is a fair assumption for the experimental data since mean velocities are one order of magnitude lower than the oscillatory component.

\section{RESULTS}

During the 3 storms the measured $H_{\text {rms }}$ decreased as the wave travelled onshore (Fig. 3a). The wave attenuation from mooring 1 to 4 was 30 to $60 \%$ in all 3 storms. In contrast, but as expected by linear wave theory, the corresponding near-bottom orbital velocities $\left(u_{\mathrm{b}, \mathrm{rms}}\right)$ increased at shallower depths (Fig. 3b). In Fig. 3 , the lag between the peaks in $H_{\text {rms }}$ and $u_{b, r m s}$ is due to the influence of the wave period, which changed within the storm.

Following the procedure described above, the equivalent roughness obtained during the third storm, on 21 July 21 , is $k_{\mathrm{s}}(\mathrm{m})=0.42 \pm 0.12$. Using $k_{\mathrm{s}}=$ $0.42 \mathrm{~m}$ and Eq. (1) for $f_{\mathrm{w}}$, the computed values of $\tau_{\mathrm{b}}$ at all moorings ranged between 12.7 and $24.9 \mathrm{~N} \mathrm{~m}^{-2}$ for this storm, so that $k_{s} \sqrt{\tau_{\mathrm{b}} / \rho} / v>5.2 \times 10^{4} \gg 3.3$, as previously assumed (rough turbulent).

At midnight on 13 July, $H_{\text {rms }}=0.65 \mathrm{~m}$ was measured at mooring 1 (16.5 m depth). For this first storm, wave heights $H_{\text {rms }}$ above $0.65 \mathrm{~m}$ were recorded for $44 \mathrm{~h}$ with maximum $H_{\mathrm{rms}}=1.31 \mathrm{~m}$. Measured $H_{\mathrm{rms}}$ normalized by the incident root mean squared wave height $\left(H_{\mathrm{rms}, 0}\right)$ at the 4 moorings is displayed for the middle $24 \mathrm{~h}$ of this storm in Fig. 4). The numerical integration of Eq. (2) and the uncertainty in the predictions, based on a $15 \%$ error in the measurement of the initial wave height and period, are also shown. Now the minimum computed $k_{s} \sqrt{\tau_{\mathrm{b}} / \rho} / v$ is $4.7 \times 10^{4}$ ( $\gg 3.3$ ). As shown in Fig. 4, fairly good agreement is obtained between the measured and predicted $H_{\text {rms }}$. Note that $H_{\mathrm{rms}, 4}^{\mathrm{m}} \approx 0.5 H_{\mathrm{rms}, 1}^{\mathrm{m}}$.

The second storm lasted $16 \mathrm{~h}$ starting on midnight of 18 July. Similar to Fig. 4, Fig. 5 presents the results for this event at $2 \mathrm{~h}$ intervals. The measured data are well represented by the predictions although
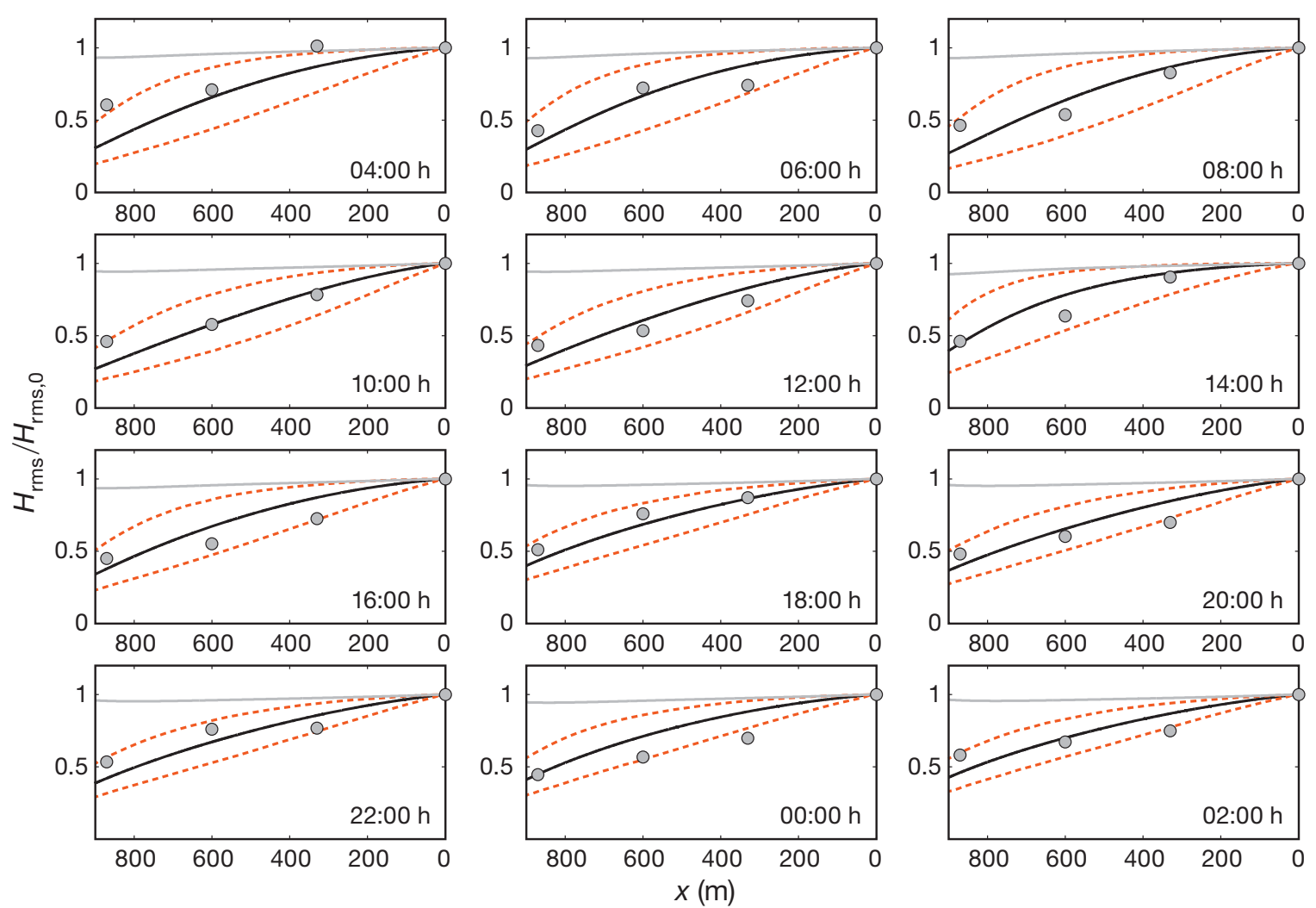

Fig. 4. Normalized root mean squared wave height, $H_{\mathrm{rms}} / H_{\mathrm{rms}, 0}$, over horizontal distance for the first storm. The plots refer to conditions every $2 \mathrm{~h}$, beginning at 04:00 h on 13 July. Solid black line: computed $H_{\text {rms }}$ including the dissipation due to the Posidonia oceanica meadow. Circles: measured $H_{\mathrm{rms}}$. Grey line: $H_{\mathrm{rms}}$ assuming no dissipation by the seagrass, i.e. $\varepsilon_{\mathrm{D}}=0$ in Eq. $(2)$. Dashed lines: predictions for wave attenuation for a $15 \%$ error in the measurement of initial wave height and wave period 

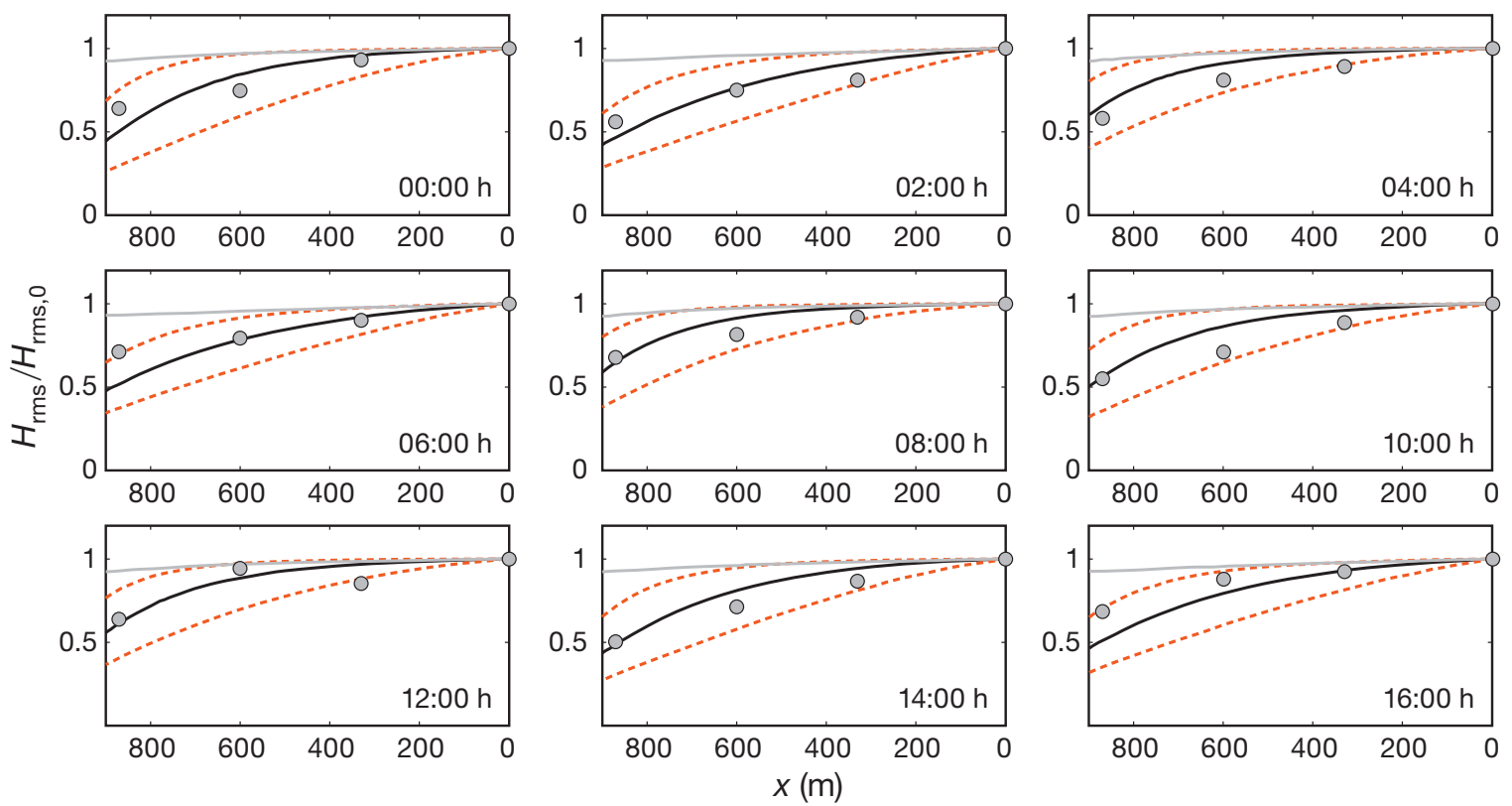

Fig. 5. Normalized root mean squared wave height, $H_{\mathrm{rms}} / H_{\mathrm{rms}, 0}$, over horizontal distance for the second storm. The plots refer to conditions every $2 \mathrm{~h}$, beginning at midnight on 18 July. Lines and symbols as in Fig. 4

some discrepancies appear at the shallow moorings. In this case $H_{\mathrm{rms}, 4}^{\mathrm{m}} \sim 0.6 H_{\mathrm{rms}, 1}^{\mathrm{m}}$ and $k_{s} \sqrt{\tau_{\mathrm{b}} / \rho} / \nu>5.7 \times$ $10^{4}(\gg 3.3)$.

For constant depth, given $k_{\mathrm{s}}$ and an incoming condition characterized by $H_{\mathrm{rms}, 0}$ and $T_{\mathrm{p}}$, the wave attenuation can be computed integrating Eq. (2) and using Eqs. (6) \& (1) to evaluate $\varepsilon_{\mathrm{D}}$ and $f_{\mathrm{w}}$ as mentioned. For a wave of $H_{\mathrm{rms}, 0}=1 \mathrm{~m}$ and $T_{\mathrm{p}}=5.5 \mathrm{~s}$ propagating over a depth of $h=10 \mathrm{~m}$, Fig. 6 displays the wave attenuation across a $1000 \mathrm{~m}$ meadow. For the computation of $f_{\mathrm{w}}$ one can consider linear wave theory for the calculation of the near-bottom orbital velocity. Because

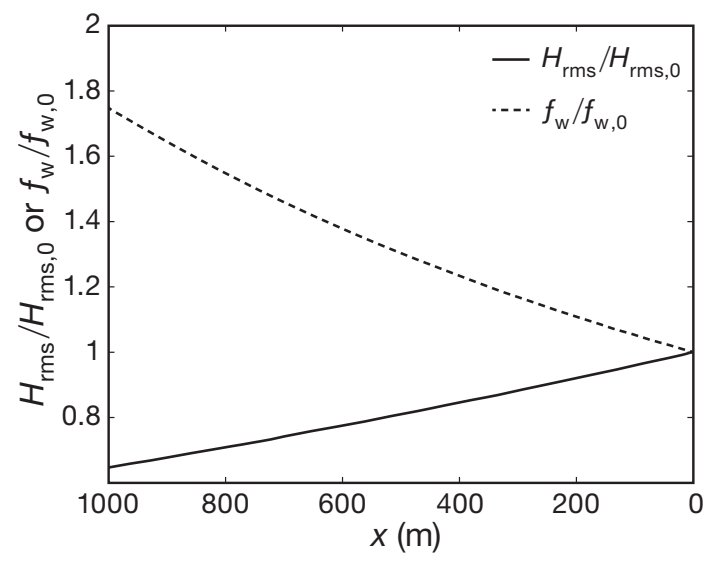

Fig. 6. Normalized root mean squared wave height, $H_{\mathrm{rms}} /$ $H_{\mathrm{rms}, 0}$ (solid line), and friction coefficient $f_{\mathrm{w}} / f_{\mathrm{w}, 0}$ (dashed line) for an incoming wave of $H_{\mathrm{rms}, 0}=1 \mathrm{~m}$ and $T_{\mathrm{p}}=5.5 \mathrm{~s}$ propagating over a constant depth $h=10 \mathrm{~m}$ the near-bottom velocity decreases as the wave attenuates over the meadow, $f_{\mathrm{w}}$ increases with distance over the meadow, according to Eq. (1), as shown in Fig. 6, so that the solution $H_{\mathrm{rms}}=H_{\mathrm{rms}, 0} /$ $1+\gamma_{x}$ in Eq. (8) is not valid.

For comparison purposes we consider the attenuation per wavelength. The attenuation per wavelength for $k_{\mathrm{s}}=0.42 \mathrm{~m}$ is displayed in Fig. 7 for $H_{\mathrm{rms}, 0}$ between 0.5 and $1.5 \mathrm{~m}$ and $T_{\mathrm{p}}$ between 4 and $10 \mathrm{~s}$, for 3 different depths. The values range from 0.2 to $3.5 \%$. As a general trend, the greater the wave height and period, the greater is the attenuation per wavelength; also, the shallower the water depth, the greater is the attenuation.

\section{DISCUSSION}

We obtained an equivalent roughness that remained essentially constant during the experiments. The values were $k_{\mathrm{s}}=0.35 \pm 0.09 \mathrm{~m}, k_{\mathrm{s}}=0.39 \pm 0.09 \mathrm{~m}$ and $k_{\mathrm{s}}=0.42 \pm 0.12 \mathrm{~m}$ for 3 independent storms. Note, however, that $k_{\mathrm{s}}$ is likely to be a function of meadow geometry (blade length and shoot density), so these values cannot be confidently applied to meadows of different geometry.

This study suggests that for incident waves with $0.5 \mathrm{~m} \leq \mathrm{H}_{\mathrm{rms}, 0} \leq 1.5 \mathrm{~m}$ and $4 \mathrm{~s} \leq T_{\mathrm{p}} \leq 10 \mathrm{~s}$ propagating over a constant depth $h=8 \mathrm{~m}$, the wave attenuation per wavelength for $k_{\mathrm{s}} \approx 0.42 \mathrm{~m}$ (corresponding to our 

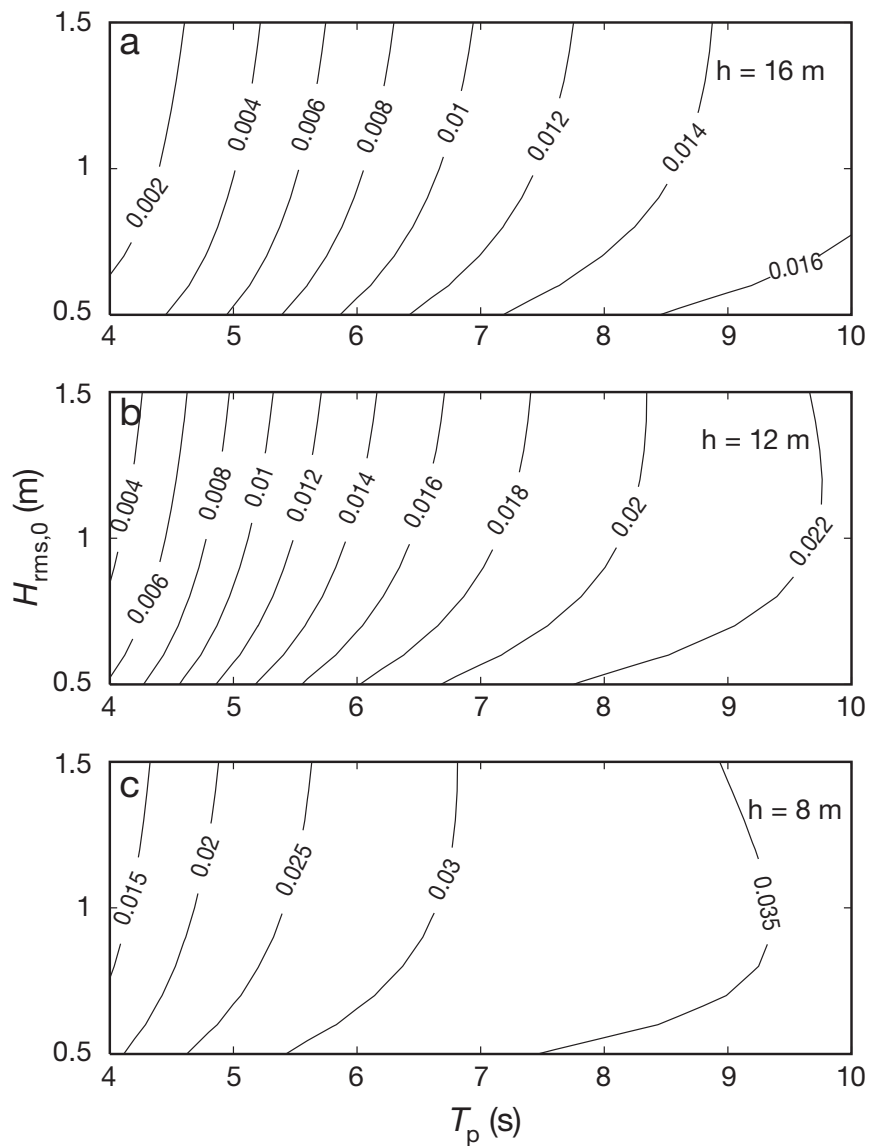

Fig. 7. Wave attenuation per wavelength for constant depths of (a) $h=16 \mathrm{~m}$, (b) $h=12 \mathrm{~m}$, and (c) $h=8 \mathrm{~m}$, with $k_{\mathrm{s}}=0.42 \mathrm{~m}$

meadow with $\mathrm{N} \approx 600$ shoots $\mathrm{m}^{-2}$ and $l_{V} \approx 0.8 \mathrm{~m}$ ) ranges between 1.5 and $3.5 \%$ Fig. 7c). Bradley \& Houser (2009), using the exponential expression Eq. (10), measured an exponential attenuation coefficient $\gamma$ ranging from 0.004 to $0.02 \mathrm{~m}^{-1}$ for waves of peak period 1.5 in water depths $h \approx 1.0 \mathrm{~m}\left(\lambda_{\mathrm{p}} \approx 3.3 \mathrm{~m}\right)$, which is equivalent to an attenuation per wavelength of 1.3 to $6.4 \%$. These authors suggest a bottom equivalent roughness $k_{\mathrm{s}} \approx 0.16 \mathrm{~m}$, which is consistent with the value obtained in this study $\left(k_{\mathrm{s}} \approx 0.40 \mathrm{~m}\right)$. The lower equivalent roughness obtained by Bradley \& Houser (2009) may be explained by the fact that Thalassia testudinum, considered in their study (with $\left.l_{V} \approx 0.3 \mathrm{~m}\right)$, is shorter than Posidonia oceanica $\left(l_{V} \approx\right.$ $0.8 \mathrm{~m})$. Fonseca \& Cahalan (1992) observed much higher rates of attenuation, but they considered conditions with leaf length equal to the water depth, which is far from the conditions we assumed, $l_{V} \ll h$. They evaluated wave attenuation for 4 seagrass species (Zostera marina, Halodule wrightii, Syringodium filiforme and $T$. testudinum) in a laboratory study. They found a $\sim 15$ to $\sim 27 \%$ reduction in wave energy per wavelength, i.e. wave attenuation per wavelength of 7 to $15 \%$.

Sánchez-González et al. (2011) studied wave attenuation due to seagrass meadows in a scaled flume experiment using artificial models of Posidonia oceanica and concluded that $C_{\mathrm{D}}$ is better related with $\mathrm{KC}$ than with Reynolds number. Specifically, these authors found that

$$
C_{\mathrm{D}}=\frac{22.9}{\mathrm{KC}^{1.09}}
$$

for $15 \leq \mathrm{KC} \leq 425$. For comparison purposes, Fig. 8 shows the drag coefficient $\left(C_{\mathrm{D}}\right)$ derived in this study versus the drag coefficient provided by SánchezGonzález et al. (2011) $\left(C_{\mathrm{D}, \mathrm{SG}}\right)$. For the comparison we used the above reported meadow values $a_{V}^{\prime} \approx$ $0.0264 \mathrm{~m}, l_{\mathrm{V}} \approx 0.8 \mathrm{~m}$ and $\mathrm{N} \approx 615 \mathrm{~m}^{-2}$ and also $k_{\mathrm{s}}=$ $0.42 \mathrm{~m}$. Recall that $k_{\mathrm{s}} \omega / u$, required to compute our $f_{\mathrm{w}}$ is related to $\mathrm{KC}$ as

$$
\frac{k_{\mathrm{s}} \omega}{u}=\frac{2 \pi k_{\mathrm{s}}}{\mathrm{KC} b}
$$

Therefore, for a given $\mathrm{KC}$, we compute $C_{\mathrm{D}, \mathrm{SG}}$ from Eq. (12) and $C_{\mathrm{D}}$ from Eqs. (13), (1) \& (7). For our field conditions, good agreement is obtained between the 2 approaches, even though $C_{\mathrm{D}, \mathrm{SG}}$ was obtained from physical flume experiments (Fig. 8).

The approach followed in the present study assumes that the water motion is mainly induced by waves. For our experiment, this is a reasonable assumption for the storms analysed since near-bottom orbital velocities measured by the ADVs are one order of magnitude larger than mean currents. In coastal environments where waves become nonlinear or currents and waves might be of the same order of magnitude, one has to explicitly solve the bound-

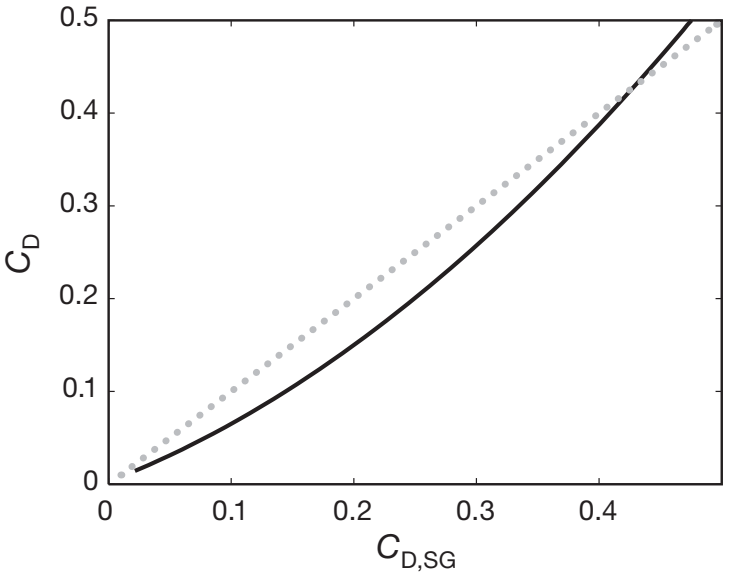

Fig. 8. Drag coefficient $\left(C_{D}\right)$ obtained from Eq. (13) versus the experimental drag coefficient provided by SánchezGonzález et al. (2011) $\left(C_{\mathrm{D}, \mathrm{SG}}\right)$. Gray dashed line: 1:1 ratio 
ary layer using a specific model (Grant \& Madsen 1979, Orfila et al. 2007, Simarro et al. 2008).

Two aspects should be considered in detail for future research. First, the link between the equivalent roughness and meadow properties has to be further explored. Second, the limitation of this approach for increasing non-dimensional blade length $\left(l_{V} / h\right)$ has to be assessed. Understanding the interaction between waves and bottom canopies such as Posidonia oceanica seagrass meadows is crucial for assessing the importance of these communities in coastal protection as well as to determine the final wave parameters which will drive sediment motion. This work shows that a $P$. oceanica meadow reduces the wave height reaching the beach. Parameters such as $k_{\mathrm{s}}$ and $C_{\mathrm{D}}$ are necessary in order to run more precise wave propagation models over seagrass meadows. Moreover, for meadows that occupy a small fraction of the water depth, it may be appropriate to use relations for bare beds, specifically Eq. (1), to characterize the drag imparted by the canopy.

Acknowledgments. E. Infantes acknowledges the financial support received from the Spanish Ministerio de Educacion y Ciencia, FPI scholarship program (BES-2006-12850). G. Simarro is supported by the Spanish government through the Ramón y Cajal program. A. Orfila and G. Simarro are grateful for financial support from Spanish MICINN through project CTM2010-12072. M. Luhar was supported on grant number 0751358 from the U.S. National Science Foundation Ocean Sciences Division. Thanks to the Club Náutico de Cala Bona which kindly made available its harbour facilities for executing the field work. Comments from 3 anonymous referees who helped to improve the work are gratefully acknowledged.

\section{LITERATURE CITED}

Boudouresque CF, Bernard G, Bonhomme P, Charbonnel E and others (2006) Préservation et conservation des herbiers à Posidonia oceanica. L'Accord RAMOGE, Monaco

Bradley K, Houser C (2009) Relative velocity of seagrass blades: Implications for wave attenuation in low-energy environments. J Geophys Res 114:F01004 doi:10.1029/ 2007JF000951

Cañellas B, Orfila A, Méndez FJ, Menéndez M, Tintoré J (2007) Application of POT model to estimate the extreme significant wave height levels around the Balearic Sea (Western Mediterranean). J Coast Res 50:329-333

Chen SN, Sanford LP, Koch EW, Shi F, North EW (2007) A nearshore model to investigate the effects of seagrass bed geometry on wave attenuation and suspended sediment transport. Estuar Coasts 30:296-310

> Dalrymple RA, Kirby JT, Hwang PA (1984) Wave diffraction due to areas of energy-dissipation. J Waterw Port Coast Ocean Eng 110:67-79

Fonseca MS (1996) The role of seagrasses in nearshore sedimentary processes: a review. In: Nordstrom KF, Roman
CT (eds) Estuarine shores: evolution, environments and human alterations. John Wiley \& Sons, Chichester, p 261-281

Fonseca MS, Cahalan JA (1992) A preliminary evaluation of wave attenuation by 4 species of seagrass. Estuar Coast Shelf Sci 35:565-576

> Gacia E, Duarte CM (2001) Sediment retention by a mediterranean Posidonia oceanica meadow: The balance between deposition and resuspension. Estuar Coast Shelf Sci 52:505-514

Ghisalberti M, Nepf HM (2002) Mixing layers and coherent structures in vegetated aquatic flows. J Geophys Res 107(C2) doi:10.1029/2001JC000871

> Gómez-Pujol L, Orfila A, Cañellas B, Alvarez-Ellacuria A, Méndez FJ, Medina R, Tintoré J (2007) Morphodynamic classification of sandy beaches in low energetic marine environment. Mar Geol 242:235-246

Granata TC, Serra T, Colomer J, Casamitjana X, Duarte CM, Gacia E, Petersen JK (2001) Flow and particle distributions in a nearshore seagrass meadow before and after a storm. Mar Ecol Prog Ser 218:95-106

Grant WD, Madsen OS (1979) Combined wave and current interaction with a rough bottom. J Geol Res 84:C4

Hemminga MA, Nieuwenhuize J (1990) Seagrass wrackinduced dune formation on a tropical coast (BancDarguin, Mauritania). Estuar Coast Shelf Sci 31:499-502

> Infantes E, Terrados J, Orfila A, Cañellas B, AlvarezEllacuria A (2009) Wave energy and the upper depth limit distribution of Posidonia oceanica. Bot Mar 52: 419-427

Infantes E, Terrados J, Orfila A (2011) Assessment of substratum effect on the distribution of two invasive Caulerpa (Chlorophyta) species. Estuar Coast Shelf Sci 91:434-441

Jonsson IG (1967) Wave boundary layers and friction factors. Proc 10th Int Conf Coastal Engineering. ASCE, New York, p 127-148. http://cedb.asce.org/cgi/WWWdisplay. cgi? 14488

Kobayashi N, Raichle AW, Asano T (1993) Wave attenuation by vegetation. J Waterw Port Coast Ocean Eng 119: $30-48$

Koch EW, Beer S (1996) Tides, light and the distribution of Zostera marina in Long Island Sound, USA. Aquat Bot 53:97-107

Koch EW, Ackerman JD, Verduin J, van Keulen M (2006) Fluid dynamics in seagrass ecology - from molecules to ecosystems. In: Larkum AWD, Orth RJ, Duarte CM (eds) Seagrasses: biology, ecology and conservation. Springer, Berlin, p 193-224

Koch EW, Barbier EB, Silliman BR, Reed DJ and others (2009) Non-linearity in ecosystem services: temporal and spatial variability in coastal protection. Front Ecol Environ 7:29-37

> Lowe RJ, Koseff JR, Monismith SG, Falter JL (2005) Oscillatory flow through submerged canopies: 1 . Velocity structure. J Geophys Res 110:C10016 doi:10.1029/2004JC 002788

Luhar M, Rominger J, Nepf H (2008) Interaction between flow, transport and vegetation spatial structure. Environ Fluid Mech 8:423-439

> Luhar M, Coutu S, Infantes E, Fox S, Nepf H (2010) Waveinduced velocities inside a model seagrass bed. J Geophys Res 115:C12005 doi:10.1029/2010JC006345

Luque AA, Templado J (eds) (2004) Praderas y bosques marinos de Andalucía. Consejería de Medio Ambiente, Junta de Andalucía, Sevilla 
Méndez FJ, Losada IJ (2004) An empirical model to estimate the propagation of random breaking and nonbreaking waves over vegetation fields. Coast Eng 51:103-118

Mork M (1996) The effect of kelp in wave damping. Sarsia 80:323-327

Nepf HM, Vivoni ER (2000) Flow structure in depth limited vegetated flow. J Geophys Res 105(C12) 28:547-55 doi: 10.1029/2000JC900145

Nielsen P (1992) Coastal bottom boundary layer and sediment transport. World Scientific, Singapore

Nortek (2002) Wave measurements using the PUV method, TN-19. Doc. No. N4000-720, Nortek AS. www.nortekusa. com/usa/knowledge-center/table-of-contents/waves

Orfila A, Jordi A, Basterretxea G, Vizoso G and others (2005) Residence time and Posidonia oceanica in Cabrera Archipelago National Park, Spain. Cont Shelf Res 25:1339-1352

Orfila A, Simarro G, Liu PLF (2007) Bottom friction and its effects on periodic long wave propagation. Coast Eng 54: 856-864

$>$ Plew DR, Stevens CL, Spigel RH, Hartstein ND (2005) Hydrodynamic implications of large offshore mussel farms. J Ocean Eng 30:95-108

Editorial responsibility: Catriona Hurd, Dunedin, New Zealand
Procaccini G, Buia MC, Gambi MC, Pérez M, Pergent G, Pergent-Martini C, Romero J (2003) The seagrasses of the Western Mediterranean. In: Green EP, Short FT (eds) World atlas of seagrasses. UNEP World Conservation Monitoring Centre. University of California Press, Berkeley, p 48-58

Sánchez-González JF, Sánchez-Rojas V, Memos CD (2011) Wave attenuation due to Posidonia oceanica meadows. J Hydraul Res 49:503-514

Simarro G, Orfila A, Liu PLF (2008) Bed-shear stress in turbulent wave-current boundary layers. J Hydraul Eng 134:225-230

Swart DH (1974) Offshore sediment transport and equilibrium beach profiles. Delft Hydr Lab Publ No. 131

- Terrados J, Duarte CM (2000) Experimental evidence of reduced particle resuspension within a seagrass (Posidonia oceanica L.) meadow. J Exp Mar Biol Ecol 243: 45-53

> Verduin JJ, Backhaus JO (2000) Dynamics of plant-flow interactions for the seagrass Amphibolis antarctica: Field observations and model simulations. Estuar Coast Shelf Sci 50:185-204

Submitted: July 18, 2011; Accepted: April 7, 2012

Proofs received from author(s): May 8, 2012 